\title{
The Conceptual Aspects of the Innovative Format of the Distance Learning System within Modern Conditions of the Higher Education System Informatization
}

\author{
Elena Yu. Bobkova1 \\ Elena V. Korobejnikova ${ }^{1}$ \\ Elena G. Nelyubina ${ }^{2}$ \\ Olga V. Birina ${ }^{1}$ \\ Lily G. Safina ${ }^{2}$ \\ ${ }^{1}$ Samara cossack institute food industry and business (branch) of the Moscow State University of Technologies and \\ Management named after K.G. Razumovskiy (First Cossack University), 443031, Samara, Russia \\ 2 Volga State Academy of Social Sciences and Humanities, 443000, Samara, Russia
}

Doi:10.5901/mjss.2015.v6n5s3p131

\begin{abstract}
The article considers backbone elements of the innovative format of distance learning system's conception. The authors offer matrix of innovative format of higher education applicable to the form of correspondence course. Base elements of the model of innovative training of bachelors and masters of distance course are stated, the criteria of efficiency of the offered model is established - an integral criteria of quality, which includes stability, controllability, capacity indexes and indicator of selforganization. The article proves the necessity of realization of the change-over to the innovative forms of the educational process's organization, namely interactive forms of study with visualizing aspect, based on the principal of the students' activity and reorganization of the available experience aimed to form psycho-pedagogical and process conditions of the necessary study material's retention. The authors believe the upgrading of educational process of remote learning system must be carried out by means of working out and introduction a special competence-oriented learning technique into the process of study. In the context of the offered conceptual approach the authors prove the necessity of introduction of innovative and interactive forms of the study process organization by means of using modern, communicative educational techniques as a complex of different ways of the theory introduction and practical lessons' organization being ministrant to activate students and aimed to form their informative-professional competence as well as upgrading the methodology of forming evaluation tools, that let an impartial and complex assessment of competence-oriented results of training.
\end{abstract}

Keywords: educational innovations, higher education, distance education, pedagogical conception, virtualization of education.

\section{Introduction}

Reforming of the higher education system stresses the necessity of working out new conceptual approaches towards the content of the higher professional education of bachelors and masters especially in the form of distance education in conditions of educational environment virtualization.

Nowadays techniques of informative nature still predominate in practice-oriented work of high school lecturers, while objective needs of society make actual the aim of general introduction of developing and personally-oriented techniques. Modernization of Russian education is oriented not only to change the content of studying subjects but also to change the approach to teaching methodology, to increase the arsenal of methodical techniques, to activate students' work during the lessons, to approach studying themes to real life through the discussion of situations and looking for the ways of solving the most burning social issues (Mukhamedzhanov B.K., 2014). Individual approach to education, the use of modern informational and telecommunicational technologies during the preparation, organization of work experience in the leading businesses of Russia and abroad define competitiveness and innovation of education in high school.

\section{Literature Review}

The current research focuses on various aspects of informatization and virtualization of higher education (Bobkova, 
E.Y.et al 2015); the problems of application of the information technologies in the educational process in correspondence course are revealed in the works of many native and foreign authors (Magsumov T.A., 2015; Mukhamedzhanov B.K., 2014; Alehin A.N., 2014; etc.), however, analysis of the leading pedagogical work experience in Russian and foreign universities suggests that nowadays the process of their use is very heterogeneous (Galkina A.l. et al 2014).

The situation of dependence of the relevant methodological contradictions in the development of the effective learning process in distance education in the theory and methodology of higher education has identified the relevance of working out the conceptual aspects of the innovative format of the system of correspondence education in modern conditions of the higher education system's virtualization.

\section{Methods and Materials}

Theoretical and methodological base of the research is made up of a systematic approach to the study of pedagogical phenomena; student-activity and competence-based approaches to the design of objectives, content and learning technologies in vocational education; psychological and pedagogical theory of developing training, ideas relevant to the integration of the content of vocational education (Kuznetsova E.M., 2014).

The research methods are analysis of documents and scientific literature, generalization of experience, observation, ranking, scaling, modeling, statistical treatment of data.

\section{Results and Discussion}

In the conceptual aspect the innovative format of the system of distance education in modern conditions of the higher education system's virtualization contains a number of basic elements, see figure 1.

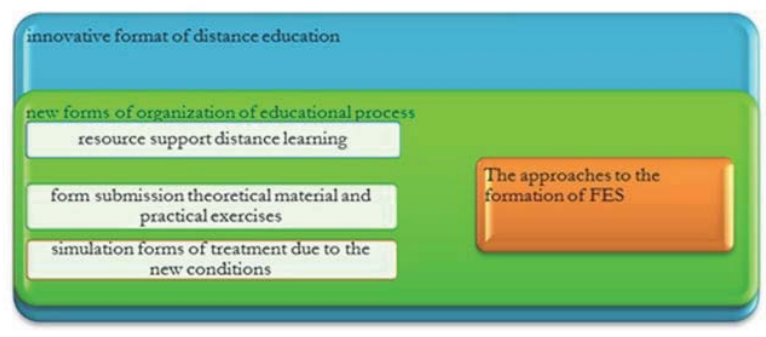

Figure 1 - The main elements of the concept of innovation format of the system of correspondence education in modern conditions of the higher education system's virtualization.

Later in this article let's look at each element in more detail. Speaking of the new forms of organization of the educational process, based on the principles of modularity and algorithmization, it should be noted that for the purpose of optimization of the educational process it seems efficient to use a model of the innovation system of bachelor's and master's degrees training in distance education, basic elements of which are presented in figure 2.

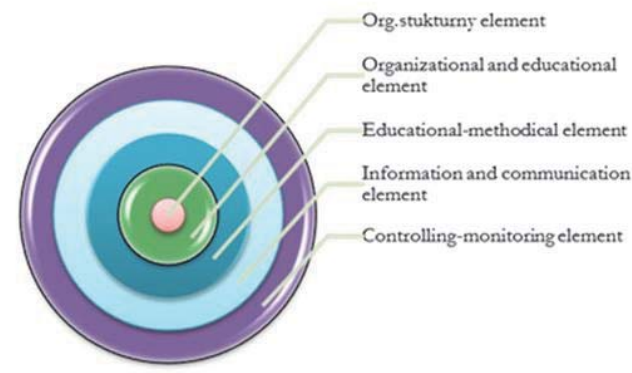

Figure 2 - The basic elements of the model of innovative bachelor's and master's degrees training in distance education 
Let's look at each element in more detail.

1. Org.structural element comprises the administration (Directorate) of the educational institution, the deans, departments and the faculty. Assessment of the functioning of the administrative element can be carried out according to the following criteria: organizational work, educational work, teaching work, qualifying potential of the teachers.

2. Organizational and educational element includes the processes of educational-methodical management, arranging the schedules of training process, class schedule, etc. "Training management" process also includes the allocation of classrooms to conduct classes. The functioning of this element is inseparably linked with the use of elements of informatization and virtualization of education, because, given the small number of classroom hours, students of correspondence form of education have to learn a lot of information in a short time. This fact makes actual the need to develop an accessible e-learning environment.

3. Educational-methodical element is responsible for the organization and direct implementation of the educational process, the development of methodological and teaching software, content filling and updating of the basic electronic components of the educational environment, etc.

4. Information and communication component is responsible for managing the documents, determines the form of documents of distance education and its location, the timely retirement of obsolete documents and making corrective changes to the documents. All components of the system of distance learning should be systematically and orderly-mannered documented in the form of work programs, guidelines, timetables, etc. All documentation must be clearly stated and put in order in compliance with the established requirements, reviewed and approved by the responsible person in accordance with the standards of the quality management system.

5. Controlling-monitoring element is a set of organizational structure, procedures, processes and resources necessary for quality management. Using this item ensures the maintenance of parameters of process of vocational training within limits acceptable to its participants to meet the demands of society, the expectations and demands of the students. This element also includes marketing activities in the educational process, as well as the study of consumer demand (potential applicants, employers), providing detailed information on the timing and cost of the training, areas of training, courses, forms of organization of educational process, etc. to entrants. The effectiveness of this element correlates with the process of saving the number of students, improving its quality characteristics.

The integral criterion of quality is used as the criterion of efficiency of the distance learning model. It includes the parameters of stability, noise immunity, manageability, capacity and self-organization. Evaluation of each of the indicators is carried out by an expertise on a number of selected characteristics.

Unlike the traditional educational concepts, where the teacher acts as a lecturer-expert, outlining the new training material, showing slides, answering students ' questions, etc., the proposed matrix of the innovation system of training gives the teacher who acts as a consultant and facilitator, whose main task is to appeal to the personal experience of students, to motivate them to solve problems independently, new data collection, etc. In this case, the teacher is out of the role of «a bearer of knowledge» for some time, charging it to a student. His aim is to support the process of establishing a new experience, to equip students with tools for success. Learning outcomes are sustainable, when the bachelor knows how to create them himself.

In general terms the aim of the teacher-facilitator is to guide the process of information exchange. That is his main difference from the role of the expert whose task is to provide information, to build and to guide decisions.

The forms of organization of the educational process are a set procedure for the organization of acts, processes, actions aimed at a more effective accomplishment of goals and objectives. Training sessions are usually held in the form of lectures, consultations, seminars, practical classes, laboratory works, tests and assessments, colloquiums, etc. The technology of training sessions is determined by many factors. The choice of technology is determined by the teacher from the point of view of management of educational process. Nevertheless, a set of didactic tools, chosen to achieve educational goals, largely depends on the form of training.

The modular training involves such an arrangement of process in which the teacher and students work with educational information in the form of modules. Each module has a completeness and relative independence. The set of such modules is a single entity for disclosure of educational topics or an entire academic discipline. For example, the target module gives a first glimpse of new objects, phenomena or events. The second module is a system of necessary information in the form of sections, book's paragraphs, computer programs. The third module includes the entire list of practical tasks, exercises and questions for self-study using the obtained information. To verify the results of mastering the new educational information the last module may be represented by a system of questions for the examination, final 


\section{exam, test, and creative tasks.}

The modular training is designed for large amount of independent work of students with metered assimilation of educational information recorded in the modules. Sometimes this type of training is called block-modular, assuming that each module is formed by dividing the curriculum into blocks (Alehin A.N., 2014).

The education process includes the set of tasks in the test form that meets the requirements of the content, form, logic and technology.

Nowadays the following set of requirements shall be presented to the tasks in the test form: a short form, manufacturability, correctness of form, correctness of the content, logical form of the utterance, the sameness of the rules of responses' evaluation, the availability of a certain space for answers, the correctness of the elements' location, the sameness of instruction for all examinees, the adequacy of the instructions to the form and content of the task.

The tasks in the test form in educational process are more often selected not necessarily on the principle of increasing difficulty, but on a thematic or other principle. For example, in the technology of modular training such tasks check the knowledge of enlarged and basic learning units studied in each module. But such totalities do not form tests. This is just a set of tasks.

The leading idea of modular technology education is the optimal partition (quantization) of the educational process at a number of component parts (units) that can be translated into Russian language as modules. The widespread introduction of computers into the educational process gave a new development of the modular technology of education. The purpose of the technology of modular training is the creation of psycho-pedagogical and technological conditions for complete assimilation of the required training material by each student (Bobkova, E.Y. et al., 2015).

The common algorithm for the development of the training module is the following: the aim of the module, the module name, a brief summary of the content of the module, written in a heuristic manner, the plan of the module, a concentrated presentation of the learning material, tasks in a test form, developmental and creative tasks, test control throughout the material of the module.

Depending on pedagogical settings as criteria of complete understanding of the module and the possibility to transit to study other module a boundary of 90 or 100 percent of information absorption is used.

The algorithm can be defined as a system of clear rules of an ordered activity. The basic requirements for the algorithm are the following: it needs to be clear and accessible to the student, correct from the point of view of purpose and content, unambiguous in interpretation and effective in the process of implementing a given number of steps. The uniqueness implies the existence of only one algorithm corresponding to the correct answer; the other terms are hardly needed to be explained. In the process of algorithmization of the process of presenting and solving tasks an algorithmic thinking is formed, which is so necessary in modern life.

Algorithmic thinking can be defined as an intellectual ability, shown in the determination of the best sequence of actions while dealing with educational and practical tasks. Typical examples of such thinking are successful performance of the various tasks in a short time, the development of the most efficient computer programs, etc.

It should be noted that using a usual form of organization of the educational process, algorithmization and informatization of the educational objectives are difficult to achieve. A well-prepared student will be able to determine the solution algorithm himself. Another situation is the organization of independent work using computers for poorly prepared students who is needed to be taught algorithms for solving problems step by step.

The use of tasks in the test form in combination with new educational technologies can provide principle improvement of the educational process through the activization of educational, monitor, organizing, diagnostic, educative and motivating functions of such tasks. The tasks in the test form combined with the modular principle of organization of the educational process provide a high level of understanding of the educational material, consistency and strength of its study.

As innovative forms of organization of educational process for distance education it is offered to transit to interactive learning with virtualization aspect, based on the following principles: reliance on the student's experience (conversion of the available experience); students' activity, teacher's position - a consultant-facilitator.

The main interactive forms of organization of the educational process for distance education include:

- on-line and off-line games;

- group and pair work using Internet communicators and functions of collective work in text editors;

- online "brainstorming" technology using Skype and social networks;

- virtual discussion;

- projects;

- moderation workshops - seminars in the framework of the modular training, carried out using moderation 
cards.

Educational technology is a system of the teacher's and students' activity in the educational process, built on a specific idea in accordance with certain principles of organization and relationship between the objectives, content and methods. In the experience of high school work various types of educational technologies are used.

Structural-logical or specified learning technologies are a gradual organization of stating didactic objectives, the selection of solutions, diagnosis and evaluation of the results. The logic of structuring such tasks can vary from simple to complex, from theoretical to practical or vice versa.

Game technologies represent a playful form of interaction between the teacher and students through the implementation of a particular story (game, business communication). The training tasks are included in the content of the game. The educational process uses role-playing, business and computer games (Bobkova E.Yu., 2011).

Computer technologies are implemented in the "teacher-computer-student" system with the help of training programs of different types (information, training, supervising, developing, etc.).

Dialog technology is associated with the creation of a communication environment, the expansion of cooperation space at the level of "teacher-student", "student-student", "teacher-author", "student author" during the stating and solution of educational tasks (Chebykina M.V. and Bobkova E.Y., 2014).

Training technology is a system of activities for the development of specific algorithms of learning and cognitive actions and ways of solving typical tasks while studying (tests and practical exercises).

Reaching the goal of improving the educational process it is offered to expand the use of mixed-training technology, combining both the students ' independent work with materials presented on-line and interactive work in the classroom, testing social and educational environment, which includes distance learning system, the website for electronic registration of listeners and other services.

The improvement of technologies of the educational process is inextricably linked with the development of teaching materials for the introduction of modern education and communication Internet technologies, educational -methodical and information resources in the environment of e-learning, multimedia educational resources.

It is also offered to use widely active and interactive forms of training (computer simulations, business and role plays, workshops, case-stages, workshops, etc.), the introduction of innovative techniques, databases, case bases and training programs in the educational process.

Another innovative pedagogical technology is conducting the moderation seminars - workshops in the framework of the modular training, implemented using the moderation cards.

Moderation workshops are based on the technology of moderation, which aim is to generalize a group professional and personal experience, to attract the creative potential of each participant in the discussion and to develop specific realizable proposals in a fairly short time, aimed at solving the target problem (Kivlyuk O.P., 2014). A moderator is the name of the leader of the discussion, as well as the presenter of an Internet forum or an e-mailing. The main thing for the moderator is to understand that during the discussion the most interesting for its participants is not the personality of the presenter-moderator, but the process of discussion itself. During the process of moderation a group of people masters the skills of active listening, open exchange of ideas, constructive criticism and mutual assessment.

The basic structure of moderation includes the following components: concentration, gathering of ideas, ranking, project work, stating an action plan.

The resource provision of correspondence courses include: the creation of the media center and infocommunication network for the full access to the joint information resources for students and teachers; implementation of automated and training systems in the educational process; computerization and automation of the process of assessment the knowledge of bachelors and masters, the use of Internet communicators, etc. (Galkina A.I. et al, 2014).

Considering the problem of improving ways to present theoretical material and practical exercises, it should be noted that this problem requires a comprehensive solution (Gaynutdinov R.G., 2014). In the framework of the proposed conceptual approach it is offered to implement a complex of various forms of lecture material introduction that will activate the work of students in the classroom: a problem lecture, a lecture-consultation, a lecture in a way of a press conference, a lecture the two together, a lecture-conversation, a lecture-discussion, a lecture-provocation, a lecture-study, a lecture with the use of feedback techniques, a visual lecture and etc. (Table1). The lectures' material should be visualized and be accompanied with the presentation materials. The text of the lecture is available to the student in electronic form. 
Table 1 - Characteristics of various forms of giving the lecture material

\begin{tabular}{|c|c|}
\hline The name of the form of lectures' organization & Feature of this form \\
\hline Problem lecture & $\begin{array}{l}\text { Problem lecture is based on the logic of sequentially simulated problem situations by } \\
\text { raising problem questions or presenting problem tasks. }\end{array}$ \\
\hline Lecture-consultation & $\begin{array}{l}\text { This form of practice is preferred while studying themes with a clearly seen practical } \\
\text { orientation. }\end{array}$ \\
\hline Programmed lecture-consultation & $\begin{array}{l}\text { It is a form of forcing the audience to join in the discussion more active. It differs from } \\
\text { a regular group consultation by the fact that the teacher makes and offers questions to } \\
\text { the students himself. }\end{array}$ \\
\hline Lecture in a form of a press conference & $\begin{array}{l}\text { Organizationally it is carried out in the following way. The lecturer, telling the theme to } \\
\text { the class, tells listeners to ask him questions in written form on the problem under } \\
\text { discussion. Within two or three minutes they state the most interesting questions and } \\
\text { give them to the teacher. }\end{array}$ \\
\hline Dual lecture & $\begin{array}{l}\text { A lecture in this form may be held by two or more teachers, intellectually and } \\
\text { psychologically compatible, using a scenario made beforehand. }\end{array}$ \\
\hline Lecture-virtual interview & $\begin{array}{l}\text { It implies the maximum inclusion of students in an intense conversation with the } \\
\text { lecturer through the skillful use of a pseudo-dialog, a dialogue and a polylogue. }\end{array}$ \\
\hline Lecture-discussion & $\begin{array}{l}\text { While presenting the lecture material the teacher not only uses the responses of } \\
\text { listeners to his questions, but also organizes a free exchange of opinions in the } \\
\text { intervals between logical parts. }\end{array}$ \\
\hline Lecture with planned mistakes (lecture-provocation) & $\begin{array}{l}\text { Its main feature is the following: at the beginning of the lesson the teacher announces } \\
\text { the theme and says that the given information will contain mistakes (the number of } \\
\text { them is not mentioned). The mistakes may be: logical, behavioral, ideological, mistakes } \\
\text { in definitions of concepts, categories, etc. }\end{array}$ \\
\hline Lecture-investigation & $\begin{array}{l}\text { In the introduction the general educational objective is stated to show the participants } \\
\text { the training problem as a whole, and to focus them on cooperated with the teacher } \\
\text { highlighting principal points, theme propositions, requiring further development and } \\
\text { research. }\end{array}$ \\
\hline Visual lecture & $\begin{array}{l}\text { It isn't read but shown. The main method of teaching in this case is showing visual } \\
\text { aids. Films, television and video fragments, slides, magnetic recordings are } \\
\text { commented by the lecturer. }\end{array}$ \\
\hline
\end{tabular}

An essential element of the considered conceptual approach is the refinement of the methodology of the formation of assessment tools. The Federal Educational Standard (FES) of higher education of the new generation is aimed to develop the students ' competencies - knowledge, skills, behavior models and personal qualities that will allow the graduate to become competitive in the labour-market, professionally and successfully implemented in a wide range of industries (Galkina A.I., 2014). Inherent in the FES approach to education differs from the traditional approach, oriented on stating a student fundamental theoretical knowledge. Traditional tools of the educational process are lectures, seminars and practical classes, laboratory works, independent work, practice, qualifying work -they all are mainly aimed at the assimilation and consolidation of the knowledge acquired during the study of certain training courses. Hence there is the priority of such assessment procedures as a test and an exam. In spite of the proven reliability and usefulness of these forms of control they cannot be considered sufficient for the evaluation of educational results in the framework of the competence approach.

In the framework of the FES of higher education the assessment of educational outcomes is a set of interrelated activities and regulated procedures by which the teacher or the commission determines the degree of conformity of the achieved educational results of the students with the requirements of the FES. Thus, the subject of the evaluation is represented as the achieved educational outcomes: professional and general competencies (outcomes), knowledge, skills, practical experience, subcompetencies (intermediate results). The purpose of the evaluation is to establish whether the existing professional and general competences, sub-competences and skills, knowledge, practical experience of the learners agree with the requirements of the FES.

Assessment is not an outcome fixation, but the point followed by a new stage of development and improving the quality of education. The main objective of this procedure is to improve the quality of teaching and learning activity of the students and, as a consequence, the achievement of a new quality of work of all educational institutions in general.

An important task is the formation of evaluative tools that allow doing an objective comprehensive assessment of the achieved learning outcomes. One must consider the close relationship between the two sides of the educational process - educational technology (ways and methods of competence formation) and methods of assessing the degree of their formation (corresponding evaluation tools). The forms of control have to become a kind of extension the teaching methods even more than before, allowing the learner to understand better his achievements and shortcomings, to adjust his own activity, and the teacher to guide the activity of the student in the required direction. Educational institutions 
independently develop and approve the basic professional educational programs (BPEP) that include assessment tools as well. The assessment tools represent a fund of control tasks and the descriptions of the forms and procedures designed to determine the quality of students' understanding of the training material. They are an integral part of the BPEP. The development of the fund of assessment tools starts right after the development of the BPEP, scheduling of classes and development of programs of all their disciplines and modules.

The structure of the fund of the assessment tools may include: a program and a schedule of organizing the monitoring and evaluation activities for the entire period of training; competency models and programs of evaluation of competencies in accordance with the specialty or profession; a set of control and assessment materials (questionnaires, tests, case studies, etc.) designed to assess the level of formation of competences on well-defined stages of learning (at the entrance for first-year students starting mastering the BPEP, after the first year of study, within the key stages of older years of education, after doing practical work, at the stage of preparation for the defence of the graduation work, etc.); training materials, defining the procedure of assessment of the competences at all stages of the review (the description of the procedures of the input control of the formation of general competences for the first-year students at the beginning of mastering the BPEP; the materials for verification of the competencies at different stages of development of the BPEP in the areas of training); technologies and methods of processing the results of competences' assessment; training materials, defining the procedure of evaluation; the sets of indicators and criteria for evaluating the level of formation of the competences and the grading scale in accordance with the objectives of monitoring; recommendations on the interpretation of the assessment results and training materials, defining the procedure of discussion of the results with the students, recommendations for the accumulation of marks and their use in the students' portfolio; a bank of statistical information and achievements' monitoring program; the structure of the portfolio and the availability of statistical information to the users (interfaces according to the users' categories: students, faculty, administration, employers, etc.); the program of the final exam for the graduates; training materials for the graduate qualification work, defining the procedure and criteria of the evaluation of the graduates' grounding to the requirements of the FES; the fund of assessment tools' update recommendations (frequency, update rate, changes in procedures, methods, technologies, metrics, criteria, etc.).

There are the following methods of assessment of the professional competencies:

1. The material or intellectual product of the learner's activity is estimated. In this context, the product is considered to be a material or immaterial result of the human work (an object, service, an idea, etc.), which can exist independently of the creator.

2. The process of the activity is evaluated (when the result of the activity is not designed as a product or the process of it is fundamentally important). In this case, the process of activity can occur in the real working conditions (professional activity) or the model conditions close to real ones as much as possible.

3. Both the result and the process of activities is evaluated.

The reasons for the choice of the assessment method are, first of all, the content of the professional activity's type and a set of tools and work objects used during the activity. In addition, a significant reason for the choice of this or that method is the type of the competence under assessment (professional or general), and also the essential resources of the assessment procedures (time, personnel, logistical, etc.).

The technology of the result of activity evaluation represents the comparison of individual characteristics with the standard based on the totality of the evaluation criteria. The comparison as a variant of the expert evaluation can be held visually, using the measurements of the individual parameters of the product, testing the product, etc. Methods of evaluating the products and activities include practical tasks and projects.

The method of the process evaluation of the professional activity is usually used when the fundamentally important thing for the assessment is the technology of implementing the job function and the related conditions (sequence of actions and operations, safety regulations' implementation, etc.). The technology of evaluating the process of activity presents a comparison of the results of the structured observation with a reference technology (technology card) on the basis of a set of predetermined and agreed criteria for assessment. These may include: an appropriate sequencing of activities, an appropriate selection of tools, the preset works' speed, if it's important to assess the competencies of this profession, the fulfillment of other specified conditions and procedures. A method of evaluating the process of activity is the formalized observation (structured observation), which is a set of standardized and harmonized procedures implemented in terms of the participant observation or in watching the video. The professional activity of the students may be organized in real conditions or simulated work situations (situation models).

Modeling the dialogic interaction in the virtual environment between a teacher and a student is primarily held in four areas: structural, cognitive, activity and socio-cultural.

Structural level of modeling the dialogic interaction gives an idea about the structure of the dialogue, about its 
major components and their interconnections. Some progress has been made by the researchers examining dialogue as a type of social interaction, i.e. the exchange of speech acts between several communicators.

Cognitive level of modeling the dialogic interaction begins already at the lower level - a speech act or an utterance, whereby all the knowledge of the lexical-grammatical character creates in the students a certain degree of linguistic competence, which is a necessary part of implementing the dialogic communication.

However, the verbal communication reveals at the level of the minimal dialogic interaction, carrying out the relationship of the replicas as the result of the process of several communicators' actions. The skill of modeling the dialogical interaction in accordance with the didactic goals of the educational knowledge is the essential characteristic of the teacher's professionalism.

The composition of the dialogic interaction at the lower level includes at least two components - the initiating and the reacting replicas. The most common type of this structuring is a question-answering dialogue structure. The ways of assimilation the question-answer structures in the learning situation should be taught in two dyads: "teacher - student", "student - student". The first and necessary pair is a "teacher - student" dyad. This is a bilateral process in which the category of speech partnerships is, first of all, realized in the creation of a comfortable psychological climate. The factors responsible for the creation of such an atmosphere are the following:

1. Expressivity and emotionality of the teacher, allowing you to create the atmosphere of a casual conversation; ("expression in this case is understood as an amplification of expressiveness, depiction of the words said, increasing its affecting force. Expression (expressivity) is a feature that is organically inherent in the literature generally and it is caused by its main aim in society - to influence the thoughts and feelings of readers, causing them to respond an emotional reaction".

2. Accessible and clear, complete and consistent presentation of both the pragmatic essence of the dialogical interaction and the pragmatically oriented phenomena.

3. Accessibility and clarity of presentation of some complex concepts that are implemented by adding to the text explanations of the emotional and heuristic aspects. The heuristic component is connected with the structure of scientific knowledge, with the style of scientific thinking.

4. A positive mutual perception at the perception level can be achieved through the introduction of different epithets to the speech, giving the overall expressiveness to the description presented, which emphasizes the significance of individual properties of the specific phenomena.

5. The desire to ensure that the proposed material has been learned. This situation encourages the teacher to use the funds, resulting in a condition, leading to a better understanding and comprehension of the material presented. The inclusion of the description of phraseological units in the text helps represent the characteristics of the presented phenomena most accurately.

6. The clear organization of the selected material with the help of systematization based on the following functions: language features that realize the communicative function as well as the function of emotional impact. Such language features motivate actions, active thinking, highlighting of important information, stimulation of conversations, and activation of the investigating activity. Along with supporting favorable climate the teacher organizes and directs the activities of students in the study of peculiarities of a professional dialogue from the perspective of both understanding its practical aspects, and ways of expression verbal means. The teacher forms a strategy, common for the both communicators, at the stage of preliminary acquaintance with the language tools and in the process of a dialogue, introduces students the rules of constructing a dialogue; directs their attention to the content of the proposed situation from the point of view of not only the structural components, but also the information saturation. At the level of "student - student" the modeling of the dialogic interaction is first of all realized when taking into account the conversion needs of each other and trying to realize a programmed plan of actions. The most emotional stress is experienced by the initiator of the communication, who quasi increases the influencing force on the addressee every time, i.e. he implements the aim to maintain the conversation. Keeping in mind the pragmatic effect, a great importance during the training is given to the teacher's consideration of the specifics of a professional dialogue; the funds aimed to form the professional communicative competence in the area of teaching the dialogic interaction; the characteristics of making one's own speech statement by the students and a free exchange of ideas in the form of a dialogue-conversation; the features of understanding the speaker by the participants of the conversation. 


\section{Conclusion}

Trying to realize an innovative format of the distance education system in the modern conditions of informatization of higher education it is necessary to turn to innovative forms of organization of the educational process, based on the principles of students' activity and transformation of the existing experience in order to form psycho-pedagogical and technological conditions of learning.

The improvement of the educational process of the distance learning system should go through the introduction of the competence-oriented learning technologies as a complex of different forms of presenting the theoretical material and the organization of practical exercises that activate students and point towards the formation of their information and professional competencies in the educational process. All facts mentioned above allows us to conclude that the implementation of the created model of the innovative teaching of bachelors and masters, studying at the correspondence course of training, is quite effective if it is based on the informatization of the entire system of education.

\section{References}

Alehin, A.N. (2014) Informatization in Education: PRO VEL CONTRA. Universum: Bulletin of the Herzen University. 2. pp. 121-123.

Bobkova, E.Yu. (2011) The formation of IPC of future marketers: the formation of information and professional competence of future marketers as a pedagogical problem (p. 196). LAP LAMBERT Academic Publishing.

Bobkova, E.Y., Korobejnikova, E.V., Nelyubina, E.G. and Likhman, V.A. (2015) Pedagogical problems of effective training of specialists in international virtualization of economic industry. Mediterranean Journal of Social Sciences. Volume 6, Issue 3S4. pp. 17-24.

Chebykina, M.V. and Bobkova E.Y. (2014) The bilingual formation of communicative competence in the process of learning marketing students in conditions modernizatsiia system of higher education. Modern innovative approaches to development of economic relations in conditions of globalization: Proceedings of the International scientific and practical conference (p. 4-13). Yelm, WA, USA.

Galkina, A.I. et al (2014) On the results of intellectual activities (RIA) based on extensive use of information and communication technologies by the example of OFERNiO materials for 2014). Chronicles of the Consolidated Fund of electronic resources Science and education. 1 (68). pp. 43.

Galkina, A.I. et al (2014) Statistics the effectiveness and efficiency of scientific support of the education system. Informatization of Education and Science. 4 (24). pp. 177-190.

Gaynutdinov, R.G. (2014) The development of the lecture as a form of learning in higher education in terms of education informatization. Kazan pedagogical journal. 2 (103). pp. 157-163.

Kivlyuk, O.P. (2014) Globalization and Informatization of education in the subject field of philosophy of education. Humanitarian Bulletin Zaporozhye State Engineering Academy, 57. pp. 192-200.

Kuznetsova, E.M. (2014) The basic processes of informatization of higher education. Formation of the humanitarian environment in the high school: innovative educational technologies. The competence approach, 1. pp. 519-523.

Magsumov, T.A. (2015) The additional professional training in the late Russian empire. Bylye Gody. (2 (36)). pp. 327-337.

Mukhamedzhanov, B.K. (2014) The Problems of teaching future teacher-trainers in the condition of informatization of education. Bulletin of the Peoples' Friendship University of Russia. Series: Informatization of education. 3. pp. 44-50. 